ISSN: $1130-3743$

\title{
IDEOLOGÍA Y ELABORACIÓN DE LA TEORÍA DE LA EDUCACIÓN: CONSECUENCIAS PARA LA PRÁCTICA
}

\author{
The ideology on Theory of Education. Outcome \\ to the practice
}

\author{
Salvador PEIRÓ I GREGORI \\ Universidad de Granada. Departamento de Pedagogía \\ Campus de La Cartuja. 18071 Granada
}

Fecha de aceptación del original: 1997

BIBLID [(1130-3743) 9, 1997, 93-113]

RESUMEN

Aparte de la introducción en materia de la implicación de los valores en educación, el autor plantea "ideología" como tema inherente a la Teoría de la Educación. Plantea las líneas de interpretación en sí misma y relaciona este concepto con el modo de contemplarlo las principales doctrinas pedagógicas. Después de asumir la ideología desde la concepción autónoma de la pedagogía, plantea prescripciones para la práctica (currículum, plan de centro, etc.). El último apartado se refiere a unas noventa referencias bibliográficas.

\section{ABSTRACT}

The author explains the implication of values in educational processes. So, he inserts the construct "ideology". At once, he describes this notion concerning principals interpretations and he chooses in correspondance with the authonomous Pedagogy. After it, the article offers the place and sense of value/ideology into same relevants Theories (doctrine teaching) of Education. Afterwards, it proposes prescriptions to the practice (curriculum, plan of action in the centre,...). Finally express references of the blibliography. 
Desde que se quebraron los 100 años de paz (1815 a 1914) se han formulado análisis de la enfermedad de nuestra civilización. Los principales son: Spengler: La decadencia de Occidente; Ortega: La rebelión de las masas; Huxley: El mundo feliz; Galbraith: Sociedad opulenta; Fanon: Los desdichados de la tierra; Marcuse: Eros y civilización; Club de Roma: Los límites del crecimiento; Russell, Eliot, Fromm, Maslow, Koestler, Steiner, etc. Lo común a todos: Sin una escala de valores aceptada e interrealizada voluntariamente por todos, nuestra civilización se resquebraja incapaz de sostenerse frente a la tecnologia y su motor, el dinero. Como ejemplos actuales, negativos y positivos, tenemos la ex-Yugoslavia, ex-URSS y nuestra España actual.

Mas, ¿conlleva esto la supresión de valores diferenciales?, ¿Se trata de un mínimo axiológico común? Y, si fuese de este modo, ¿se extrae que para las escuelas e institutos sólo habría una escala de valores? Entonces, ¿cómo plantear las divergencias opcionales en las elecciones para los Consejos Escolares?

Reducir la dignidad valoral a una es impensable. Maslow convocó en octubre de 1957 un simposio en el MIT sobre los posibles fundamentos de una escala de valores nueva. Alli se palpan (Racionero, 1996) tres tendencias: I. Bronowski y von Bertlanffy basando los valores en la ciencia, tomando la supervivencia y la evolución como criterios ineludibles. Es el NATURALISMO con base en la Biología. Lo científico como fundamento en la sociedad laica es congruente. Pero, ¿No está cambiando continuamente la ciencia? Igual sirve para justificar la competencia como la cooperación. II. Fromm y Maslow los derivan de la naturaleza humana, usando como criterios la salud y la autorrealización. Se trata del HUMANISMO fundado por la Psicología. Esta "ciencia" ha sustituido el confesor por el psicoanalista y los ejercicios espirituales por la psicoterapia; pero: ¿Cómo saber a ciencia cierta cuál y cómo es la naturaleza humana? III. Tillich y Zuzuki los fundamentan en una instancia metafísica que apelaría a la salvación y a la obediencia. Está en la ONTOLÓGICA con base en la Religión. Esto se hacía antes del XVIII. Entonces, ¿Una nueva religión? ¿Se pueden compaginar los tres?, ¿Es difícil llegar a esto?, ¿Qué consecuencias trae para pensar la educación?

\section{Los Valores COMO Datos Para El SIGUIENTE Discurso PEDAGÓgICO}

Las derivaciones de las definiciones de educación consideradas por García Carrasco y García del Dujo (1996, 47 ss.) expresan la idea de acción y la de modificabilidad del comportamiento en función de valores o normas internalizadas.

La actuación educacional se compone de una serie de procesos (Esteve, 1983), de entre los cuales subrayo instrucción, formación y educación. Simplificadamente, la primera da construcción dentro del sujeto de estructura intelectual, es medio para; la segunda despierta en el educando el sentido que tiene la cultura para sí, por ende, qué propósitos ha de formularse y qué responsabilidad exigirle y aplicarse, lo cual es clave en democracia y exige un nivel de razonamiento moral mínimo; la educación conlleva el ejercicio de la voluntad, es habituación (Escámez, 1981) con previa toma de sentido. Esta no es un mero comportamiento estereotipado del hábito conductista, periférico al sujeto. Por consiguiente, la previa valoración de tales virtudes es clave para salvar el binomio tan frecuente de instruc- 
ción-habituación. Así que, formar la conciencia es paso correlativo al de la voluntad. De aquí la relevancia del valor en el discurso teorético.

Es por esto que, no sólo los padres, los teóricos de la pedagogía debemos abordar el estudio de los Proyectos educativos de centros, de etapa y de aula. ¿Qué tipo de hombre se pergreña?, ¿Se abordan todas sus dimensiones y ámbitos?, ¿Llenar cabezas, formarlas o también se atiende al carácter?, etc. Ante esto se exige una hermenéutica antropológica de tal documento. Es entonces cuando el padre podrá elegir con criterio; es cuando el teórico podrá informar, denunciar, señalar, ...proyectos mancos, inacabados, etc., por dejar lo afectivo, ser superficiales en lo cognitivo, etc.

En el sistema democrático occidental, el poder se legitima y justifica en los valores aceptados por la sociedad. Estos solian fundamentarse para todos en una instancia superior metafísica que, en Europa, hasta el siglo XVIII fue la religión cristiana. Hacia el año mil se configura por la fusión - más o menos lograda - del igualitarismo cristiano y el individualismo bárbaro barnizados por una capa formal de humanismo grecolatino y de ciencia hebreoislámica.

Hoy se observa la no total integración pero con las siguientes tendencias: a) individualismo bárbaro, en economía de mercado en forma de iniciativa individual, agresividad competitiva y liberalismo mercantil; b) igualitarismo cristiano, opuesto a: desigualdades económicas, insolidaridad y el poco respeto a los menos privilegiados. De aquí que Naval (1996) proponga una serie de virtudes sociales para el logro de la educación cívica: piedad, honor, tolerancia antiracista, autoridad, orden, veracidad, etc. Pero no todos ven igualmente esta solución.

Entonces, ¿qué valores enseñar en el sistema educativo? La escuela es el lugar especializado en lograr la humanización de los educandos. Esto conlleva el dar criterios y valores éticos para orientar responsablemente el comportamiento para los diferentes campos de la vida. La escuela es la agencia idónea para dar un tratamiento sistemático de formación moral.

La libertad es un valor que no se efectúa sin la presencia de otras dimensiones axiológicas. Se trata de valores más permanentes que la pura libertad: de que cada uno crea y haga lo que quiera. Aparte del tratamiento sistemático, ¿Caben lecciones o alusiones ocasionales de carácter ético en diversas disciplinas? Sistematizar lo exigible para ser ciudadano entre lo individual y lo comunitario (Naval, 1995), ¿Y estudio de casos sobre el ambiente ciudadano (McEwan, 1990) del aula o centro?

Por lo referido sobre la influencia de los valores en la educación, entiendo que los valores son referentes necesarios en una sistemática democrática (Andrews, 1995; Diesser, 1991), pero también para hacer frente a las crisis derivadas de un mundo cambiante (Paul y Binker, 1990); es más, en una situación sociocultural como la nuestra, que se está configurando como multicultural, la pluralidad de opciones incide en los diseños educativos de los centros (Banks, 1993), por lo que la teoría no puede enajenarse de la cuestión.

\section{LA IDEOLOGÍA COMO PROBLEMA TEÓRICO EN EDUCACIÓN}

Por lo antedicho, queda justificada la concreción de la intencionalidad del mundo de la educación en buena parte de su contenido mediante valores y con- 
cepción del hombre y de la vida. Por esto, es difícil encontrar realidades asépticas en Pedagogía. Sarramona $(1988 / 89,69)$ resalta la sensibilidad que el ámbito educativo mantiene con las ideologías, pues "la misma naturaleza del hecho pedagógico lo fomenta, ya que la educación se efectúa en función de patrones vinculados a modelos filosófico-sociales". En este sentido, ¿Entienden todos de igual manera este concepto?

Para Marx ideología significaba un conocimiento no objetivo, sino reflejo de la infraestructura económica y de la propia situación en la lucha de clases; por tanto, la manera ilusoria y elevada de tomar conciencia de sí mismo y de la sociedad a partir de intereses creados.

Mas, por lo conocido sobre la estructuración de las personas, comunidades e instituciones, las ideologías existen y han existido siempre, desde los albores de la civilización las hubo, aunque no se llamaran así (Fontán, 1995, 55). Este es el sentido en que las encontramos en parte de los poemas homéricos o valores propuestos por los patriarcas bíblicos. Lo que sucede es que con la ilustración se formaliza con este substantivo (Condillac) y los "ideólogos" franceses (Destutt de Tracy, Volney, Cabanis,...) la desarrollaron en un pensamiento político pedagógico antimetafísico para expandir la revolución francesa. De aquí la conexión con la imagen peyorativa dada al vocablo por Marx. Este es el sentido dado en La ideología alemana, que expresa doctrina de identificar la ideología con los intereses políticos, propugnando extirparla revolucionariamente. Para él, las ideologías no explicaban nada porque pertenecían al orden de las superestructuras, eran restos rancios del pasado y no servían para nada, son opio.

Ibáñez Langlois (1990, 247-248) también señala que ideología viene a significar un sistema de ideas simplificado para el uso masivo y con fines de conquista y ejercicio del poder. Esto suele implicar lo siguiente:

a) elementos "a priori" de intereses creados, ajenos a la pureza gnoseológica de una verdadera doctrina;

b) un alto grado de abstracción, esquematismo, vaguedad e imprecisión;

c) intensa carga afectiva y emocional, que subyace en los conceptos abstractos;

d) visión reductiva de la naturaleza humana, a menudo de signo economicista;

e) elemento utópico de frecuente carácter gnóstico o con carácter escatológico secularizado.

En este sentido, la ideología esta situándose en un relativismo. Entonces ya no se debe pensar en ciencia, pues hay abstención de cualquier forma de certeza. Se duda de todo, no hay posibilidades de diálogo. El criticismo emplea el eslogan y la duda como método. Incluso se finge que se duda, y se duda de la aptitud de conocer.

Otra concepción que repudia de modo semejante es la centrada exclusivamente en la eficacia, el pragmatismo. A esto pudiera referirse el Aron maduro en sus memorias bajo el concepto de ideocracia (Ibáñez-Langlois). Unos y otros buscarían un consenso ideológicamente neutro con el fin de evitar la infelicidad ciudadana.

Una fundamentación antropológica que conciba al hombre como un ser libre y responsable, y a los sujetos, grupos y comunidades como realidades instaladas en un tiempo y lugar determinados — Welt, en la historia-, ha de aceptar las ideolo- 
gías tal como se dan y ha de postular un sistema en donde puedan competir los hombres. Ya que, luchar con palabras en vez de con espadas es la base misma de nuestra civilización (Popper), es la herencia de la democracia ateniense.

Y no es una afirmación gratuita, según Fontán (1995: 60-61) éstas establecen... a) un sistema de creencias, opiniones en relación a sistemas de valores; b) se apoyan siempre en una filosofía, respondiendo a las cuestiones últimas sobre el hombre, la vida, la comunidad, etc.; c) son operativas, o sea: producir actitudes y comportamientos; d) compartida por una comunidad, por lo que no son: d-1) ni convicciones (éstas son individuales), d-2) ni una concepción del mundo (ya que ésta igual puede compartirse que mantenerse subjetiva; e) en su funcionamiento social, las hay que poseen una gran capacidad para asimilar los conflictos, lo cual hace posible la integración de los valores suyacentes a esa ideología con los de otra, o por lo menos su coexistencia, como es el caso de la liberal; f) las ideologías mayoritarias actúan como factor de cohesión, siendo vías para llegar al consenso; g) las minoritarias mantienen la crítica, no sólo en cuanto al control, sino en actos mucho más radicales; $\mathrm{h}$ ) ordinariamente dependen de los valores recibidos, muchas veces no conscientes, como son las tradiciones, costumbres, etc.; i) es susceptible de sistematizarse en forma de teoría, lo cual se distingue de mentalidad, que es particular e inseparable del sujeto que la siente; $\mathfrak{j}$ ) por consiguiente, son comunicables, objeto de enseñanza en forma de doctrina.

\section{Sentido de la ideología para la sistematización de la educación}

La ideología es un sistema de representaciones, ideas de valor y normas que sirven al individuo, a un grupo social o a una sociedad entera para interpretar el sentido del mundo. A este conjunto organizado de ideales les pone el rango de valores y normas. Esto mismo es lo que integra y les capacita a sus miembros para la acción (Lemberg, 1971). Esto trae consecuencias decisivas de cara a la fundamentación de la teoría educativa. Carr (1990: 155), citando a Peters, atribuye a la teoría analítica la idea de que la razón no puede desarrollarse en un vacío social. La condición para rellenarlo es la inclusión de principios de vida democrática: libertad, tolerancia, igualdad, respeto, etc. Esto significa un paso más, consiste en introducirse en una teoría material.

El mismo Carr, citando a uno de los fundadores de la teoría crítica - Habermas-, plantea el análisis del concepto de discurso, concluyendo en la consecuente resolución de las cosas mediante el diálogo crítico, exigiendo sinceridad y justificación de lo expresado, a la vez que racionalidad, comunicatividad y consenso racional; asimismo que el razonamiento se emancipe de ideologías (p. 156). Por lo que, a la vez que plantea ciertos valores, rechaza lo axiológico globalmente en tanto que ideología. En esta línea piensa Moore (1980), al mencionar la manipulación y adoctrinamiento, pero no sólo por ofrecer, sino también por conculcar valores tipificantes, configuradores, de un tipo de hombre. Por lo que desde ésta, podemos decir, tendencia analítica pura, se rebate el autonomismo, a la vez que cae en un cierto uniformismo. Esto es porque los valores los toma de lo que hay en la sociedad y en ese tiempo. 
Para la teoría personalista, la cultura no son unos valores sin más, sean estos intelectuales o materiales. Esta "presupone y reclama una visión del hombre integral, captado y comprendido en la totalidad de sus virtualidades morales y espirituales, en la plenitud de su vocación. (...Es) actitud crítica y activa por la que el hombre ni se somete a la cultura dominante, ni cede a la tentación de ignorarla o anatematizarla, sino que la asume con plenitud viviéndola y juzgándola desde la fe y en la fe" (Illanes y otros, 1984: 42). En este sentido, al plantear la axiología como teoría de los valores (Marín, 1968), se recogen estas conclusiones dentro de su sistemática. Consecuentemente, decir que "los valores educativos están condicionados por los valores culturales y por la axiología general" (Fermoso, 1976: 144), implica una reflexión hecha desde la Teoría de la educación que conjuga ambos ámbitos de conocimiento.

Corolariamente, no podemos ver como Bruner (1987: cap. $2^{\mathfrak{Q}}$ ) que los valores y el lenguaje sean limitadores culturales del desarrollo cognitivo. Con Brezinka (1989: cita a Lemberg) asumimos que para la conducta vital del hombre no basta el pensamiento racional y científico solamente, sino que son necesarios también los actos emocionales de la fe, las creencias, ya que estos incluyen una imagen del hombre. En este sentido reconocemos que la política educativa española sigue esta línea pedagógica. Lucini (1990) plantea directrices para interpretar el diseño curricular de modo abierto (p. 71), señala que educar en valores trae el acompañar a los niños, adolescentes y a los jóvenes en el proceso de respuesta libre y personal a interrogantes como estos: ¿Quién soy?, ¿Hacia dónde camino?, etc. (p. 17). Siendo los valores fundamento para la existencia y proyecto de humanización de la acción educativa (p. 29), porque busca como objetivo prioritario la configuración unificada de la personalidad (p. 70).

Respecto a este último enunciado, ¿No podemos interpretar como equivalentes unificada con ajustada consigo mismo? Porque unificar, en sentido uniformista entra en contradicción con el ¿Quién soy? Además, las coordenadas de la estructuración del yo (Castilla, 1994) plantean que los valores relativos al ajuste son el compromiso y la fidelidad, en tanto que se erigen para vivir con otros - comunidad-.

Este planteamiento tiene fundamentalmente relevancia para la vida académica. Toda institución se estructura en tres dimensiones culturales (Shipman): instructiva, normativa y expresiva. El ideario o proyecto educativo es lo que da sentido a las partes. No se trata de una uniformización, Lucini (1990: 21) ve el ideario como presentación de alternativas de valor, comprometerse, aportar a alguna de las áreas axiológicas, sometiendo a las demás a un proceso de crítica razonada y objetiva.

Por consiguiente, la noción de ideología hoy es una realidad tan viva que es necesaria para dar sentido a los procesos educativos y exponer tal manera de ser para posibilitar la elección con criterio claro. Por tanto es fundamental para materializar opciones en pro de la libertad en educación.

De aquí la clarificadora definición de Marín (1976) de educación como realización de valores en el individuo y en la sociedad, pero no de uno ni parte, sino de todos y en armonía. Definición cada vez más actual y necesaria, por sus vir- 
tualidades de fundamentación y operativas. Pensemos en la materialización de los idearios de los centros, allende los proyectos curriculares que piden acabamiento sistemático. No es menor la exigencia de las sistematizaciones de cárceles, centros infanto-juveniles, especializados, con las intervenciones para sujetos exigentes de reeducación.

Por consiguiente, si desde la sociabilidad del sujeto se justifica la ideología; si desde la perdurabilidad de las comunidades - con todas sus consecuencias- es necesario este sistema trascendental; si uno de los motivos que justificaron la institucionalización de la educación era la comunicación — "traditio" - de lo trascendente a los meros intereses individuales, queda clara su relevancia pedagógica. Mas, ¿Cómo se comparte desde la Pedagogía?

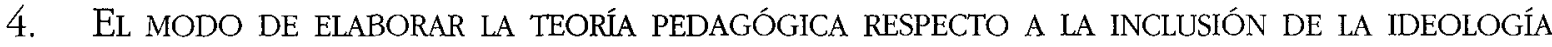 EN LOS PROCESOS DE EDUCACIÓN}

La intencionalidad se concreta en normas para efectuar la pedagogía práctica. Mas, por ser un contenido axiológico o tecnológico, no podemos discurrir por el verdadero/falso. Como dice Fermoso (1990: 48), requieren una justificación. Etimológicamente de ius, o sea: amparar por derecho tal decisión.

Pero, esto es insuficiente e incompatible con el realismo, si se toma escuetamente. El positivismo jurídico sólo ve lo legislado y aplica un deductivismo rozando lo abstracto. Nosotros sabemos que hay algo que confiere sentido a la disposición, es la matriz antropológica y la orientación axiológica. Este debe ser el sentido dado por Fermoso, pues añade: mostrando la oportunidad, conveniencia y falta de contradición con los saberes. Así, junto al derecho y la razón. Y continuando con los planteamientos del profesor de Bellaterra, combinando propuestas de Hare, 1966; Moritz, 1966; Bellmann, 1975; Richards, 1971; Habermas, 1971,...), define que la justificación puede efectuarse por cinco vías: 1) Demostrar que lo preceptuado es realizable, puede cumplirse. 2) Elegir lo óptimo, según tales planteamientos. 3) Probar su utilidad, en relación a los objetivos. 4) Persuadir que esta alternativa es mejor que otras propuestas. 5) Respaldarla, bien por criterio de autoridad o por consenso. 6) Garantizar que es muy difícil contradecir la norma dada.

¿Quién lo justifica?, ¿Desde qué matriz disciplinar? Ir más allá del positivismo jurídico, o del sistema de recetas dados por leyes subalternadas. Esto reclama las disciplinas teoréticas de la educación. Estas, sin romper el nexo teoría/práctica, parten de las teorías sobre objetos reales, tanto empíricas cuanto metafísicas, desintegran y recomponen el ser, el conocer y el valor. Propugnan (Fermoso, 1990: 49-51) la Teología, Filosofía, Axilogía, Pedagogía científica, Pedagogía tecnológica y Política. Así se abordan problemas según materias (Marín, en Brezinka y otros 1989; Cirigliano, 1973): del ser, definiciones, antropología, voluntad,..., qué es lo real en educación, de qué está compuesta, cuál es su realidad última; del conocer, epistemología, metodología, gnoseología, la verdad,..., cómo conocemos la educación, qué se puede conocer de ésta, hasta dónde conocemos, y del valor, axiología, el bien educativo, afectividad, ...qué es lo bueno, lo bello, lo malo, qué debo hacer, de dónde extraer normas para la acción. 
Por otra parte, si analizamos propuestas como la de Popper (1992), veremos que lo teleológico y para procesos informales de educación va más allá del binomio ley-fines. Este propone (para la) educación: la protección del niño frente a la exhibición de escenas de violencia en los medios de comunicación (propaganda pro violencia e incluso propaganda en pro de la unión entre sexo y violencia). La exposición de niños en la exhibición de tales escenas debería considerarse delito, lo cual conlleva hablar de censura. Pero la libertad tiene sus límites y, si no nos autolimitamos voluntariamente, deben imponerse unos límites: lucha contra el crimen y mejora de fuerzas de policía, servicios penitenciarios y jurídicos. ...Esto debe pasar - indica - de la ideología a la ingeniería social, con apoyo de una tecnología social.

Desde otra vertiente, podemos observar las concomitancias científico-ideológicas. ¿En dónde situaríamos lo ético en la ciencia? Desde la teoría analítica (Woods, 1976: 29 ss.), la capacitación para efectuar el discurso filosófico no sólo se demuestra por la implicación directa de la normatividad. La Teoría de la educación está directamente relacionada con la teoría pedagógica al verificar la idoneidad de ciertos juicios de valor a través de definiciones persuasivas y uso afectivo del lenguaje, que están comprendidos en las categorías de adoctrinamiento, o en la metáfora de desarrollo. También, desde ésta, se entiende que la Teoría de la educación debe intervenir al observar que el proceso educativo va equivocadamente. Esto lo materializan en su aplicación detectando presunciones y suposiciones que conciernen a las creencias de la gente, sus valores e ideas y que influyen en la dirección de acciones educativas. Cabe razonar contestando a esta cuestión: ¿Hasta qué punto deben éstas dirigir la acción? Además, desde el planteamiento teorético, hay que generar habilidades para detectar errores en el razonamiento, en juicios y, para éstos, suprimir los metafísicos. Finalmente, añade Woods: forzamos a efectuar preguntas sobre la naturaleza del conocimiento, pues hay un número limitado de maneras de conocer relativas a un número también limitado de formas de conocimiento.

Mas, éste es un enfoque que requiere suplementación, como decía más arriba. Veamos, mediante un ejemplo, una de las dimensiones del objeto de la Pedagogía Social. Supongamos que una comisión de científicos sociales prepara un programa antidroga. Se requerirá un estudio previo, el examen sobre el estado de la cuestión, recopilar lo fáctico - descripción- que es independiente de intereses particulares. Luego, al clasificar los hechos, ya se empieza a valorar, pues no habría razón para diseñar un programa alternativo de actuación, lo cual sería el último estadio, con la intervención técnica. Si bien el estudio puede realizarse sin intención de mejora, bien pudiera ser con intención de "marketing", el diseño ya supone la optimización, una ética, un modelo de hombre. ¿Es esta postura una ideologización peyorativa?

Para contestar a la cuestión, antes afirmo que siendo objetivo, uno no debería ser identificado como neutral, impasible. La identificación de cosmovisiones o de ideologías subyacentes bajo la cáscara de lo fáctico, se brinda como instrumento para comprender la coexistencia de ideas disímiles de la educación. Tocar las raíces de esa diversidad y transformarlas en componentes de las conceptuali- 
zaciones pedagógicas, es echar a andar por los caminos de la objetividad, al menos de la permitida y factible en las ciencias humanas. "Sólo una actitud objetiva (Nassif, 1983, p. 19) puede darnos cuenta de lo real tal cual es, en sí y en sus conexiones con otros objetos. Si ese objeto está histórica e ideológicamente condicionado, tales condicionamientos han de insertarse en las conceptualizaciones pedagógicas. Por eso éstas son 'objetivas', aunque no tengan que ser indefectiblemente y totalmente 'neutrales'".

Racionalmente cabe insertar esta modalidad del discurso dentro de las conclusiones y recomendaciones derivadas de una teoría, aunque teniendo presente que no se debe forzar su sistema. Pero, valga el ejemplo para comprobar el alcance de la ideología en Pedagogía, así como el proceso de justificación de proposiciones teleológicas.

Con el fin de que tales prerrequisitos se cumplan, para que el salto epistemológico no llegue a darse. La teleología inserta en la misma sistemática pedagógica surge en la relación existente entre descripción-explicación, explicitándose muy claro el nexo real entre éstas y la norma propuesta en su doble acepción: axiológica y tecnológica, así como la síntesis que supone el acto educativo. De este modo, la conexión se da ante la delimitación del proceso educacional y la elaboración de la acción a través de sus "componentes" estructurales (Castillejo, 1987). De esta manera se entiende una Pedagogía, abierta a los valores, pero respetuosa con las dignidades intervinientes, sin dogmatismos que, por otra parte, en ciencia son insostenibles.

Otra perspectiva nos alumbra para ilustrar la racionalidad pedagógica general. El discurso de Escámez (1994) que relaciona la intervención educativa con los valores y la LOGSE. Desde esta materia racional el autor no se ocupa en elaborar una lista axiológica a diseminar por los centros. Al preguntarse por los valores en qué educar, no acude al discurso pedagógico, sino que introyecta en éste los resultados de otra racionalidad: "valores coherentes con los derechos humanos; aquellos valores explícitamente formulados en nuestra Constitución; alcanzar acuerdos generalizados, y que los diseños curriculares básicos, cuando presentan los contenidos referidos a valores, actitudes y normas". Por consiguiente, concretar fines es fruto de otra racionalidad que no es la de la ciencia de la educación.

Pero, ¿Significa esto aceptar las propuestas de cualquier racionalidad, acuerdo, pacto o consenso? Aquí cabe el papel de la teoría. Con ésta miramos a la vez la realidad educanda y la legislada, pactada o elaborada por procedimientos de justificación. La racionalidad pedagógica yace sobre la matriz antropológica, que establece las condiciones y sentido para efectuar la hermenéutica. De aquí el sentido de la crítica, cuya premisa nos viene dada por el citado profesor valentino. ¿Qué valores son ésos? Se trata de los ideales que respondan a los parámetros de la persona: valores materiales, vitales, personalizantes, sociales, políticos, éticos, estéticos y trascendentes; ya sean religiosos o cosmovisiones. Además, consecuentemente, revisa la intención del legislador, mediante el Libro Blanco de la Reforma. Es decir, no efectúa una racionalidad política, sino que estudia sus conclusiones. Al final surge la crítica pedagógica, fruto de la teoría filosófica, constatando la presencia de las áreas axiológicas o en detrimento de otras por ausencia 
o conculcación en educación infantil y primaria. Este es su juicio: "Sin embargo, los valores materiales y éticos son muy insuficientemente atendidos o nada atendidos como es el caso de los valores políticos y trascendentes.

Cuando se admiten dogmas fuera de las fronteras de la Religión, se cae no sólo en el absolutismo cientificista, sino también en la negación de la creatividad y la innovación. Si la ciencia es absolutizada se llega hasta a eliminar la verdad filosófica; por lo tanto, en vez de lo que pretende ser, es decir: conocimiento puro, se transmuta en una "anti...", entonces es harto fácil convertirse en un arma en la que la verdad no cuenta. Son ciertos eslóganes que aseguran que "las ciencias son verdaderas" porque satisfacen ciertas pretensiones (intereses) de grupos de los que son instrumento.

Al ser regulados los procesos educativos por la ciencia, no pueden hacer caso omiso de un contenido ideológico, ya que el modelo con que captan y predicen la realidad está impregnado de un patrón valioso sobre la concepción del hombre (Brezinka, 1989). Este juicio es homólogo al del párrafo anterior, pero plantea un nuevo problema. La mención de la Teoría de la educación en el primero, ¿Supone aquí la parte antropológica, la axiológica o criteriológica? Además, ¿Cómo es posible que la teoría científica de la educación integre tales matrices humanísticas?

A parte de las consideraciones dadas desde la necesaria dependencia de la educación respecto a los valores, ¿Qué hay en relación a la criteriología para efectuar el discurso pedagógico? Con el fin de iniciar la respuesta a la cuestión, tengamos presente las proposiciones de Touriñán (1987, 78-79), al indicarnos las cuatro tesis siguientes, matizadas por unas apostillas propias:

a) La ciencia, según interpretación positivista, no es suficiente para resolver los conflictos morales, pues hay que dar un salto lógico para resolverlos. Pues, éstos son más bien planteamientos axiológicos; y, saliéndonos del pensamiento del profesor de Santiago, la perspectiva axiológica se basa (Cruz, en GER, 528) en que, muchas cosas que son, no por ello juzgamos que valen, incluso nos dejan indiferentes. Y, volviendo al pensamiento de Touriñán, entre ser y valor hay órdenes epistemológicamente diversos.

b) El propio proceso de intervención genera sus propias cuestiones acerca de sus metas a resolver desde un marco de la racionalidad científica. Es lo que indicaba unas páginas antes (Touriñán, 70-71): “la función pedagógica no equivale a saber tanta historia como el historiador, sino saber qué objetivos se logran al enseñar este tema de historia; qué destrezas, hábitos, actitudes y conocimientos debe poseer el alumno para aprender ese tema...."

c) Hay temas morales compartidos y cuestiones limítrofes de crisis axiológica. Lo que se concretaría con un ejemplo, siguiendo la cita del autor en la reflexión anterior (70-71): "...y qué razones hay para utilizar ese tema y no otro como instrumento pedagógico". A mi entender, ésta sería una cuestión que bien podría dilucidar el llamado ideario o carácter propio de un centro.

d) Decisiones morales y pedagógicas no se confunden. Ni lo moral se resuelve con conocimiento pedagógico, ni lo pedagógico con juicios éticos. La última ejemplificación no surge esporádicamente, requiere dilucidar este problema. Lo 
cual no se realizaría desde el razonamiento pedagógico, es necesario saltar a estrategias que, si bien se plantean desde el discurso de la ciencia de la educación, han de resolverse desde discursos teológicos, filosóficos, convergiendo o no con pactos y convenciones.

¿Se da la pretendida ausencia ideológica en las corrientes positivistas, negadoras de cierta carga valoral? No, pues, mostrando frutos emanantes de escepticismo, Lenzen $(1988,83)$, contesta indicando que se trata de un enmascaramiento. $\mathrm{Y}$, siguiendo su mismo discurso, también mete en la misma órbita a las explicaciones que meramente reaccionan contra lo llamado medieval, así como a los estructuralismos. Concluye en que eso no es Pedagogía sistemática. En esta línea, mas con actitud positiva, Nassif $(1983,18)$ resuelve la cuestión apelando al encuentro con lo personal, que relativiza el afán positivista. Estas son sus propuestas: "En la indagación pedagógica, al igual que en todas aquellas en que el hombre-investigador se superpone al hombre-investigado, la humanidad del pedagogo tropieza con la humanidad de la educación. Entonces, su afán de objetividad conceptual sufre el impacto de sus compromisos epocales, ideológicos y personales, mas no por ello ha de abandonar el buceo, sino de conceptos absolutamente objetivos, por lo menos de nociones comprensivas y orientadoras... Cuando la pretensión de lo concreto alcanza grados obsesivos, se incurre en grave error metodológico, cómodamente recostado sobre la renuncia a construir o a emplear principios orgánicos para comprender los hechos educativos y para diagramar las investigaciones pedagógicas básicas".

\section{INTERPRETACIONES DE LO VALORAL Y POSICIONAMIENTO TEORÉTICO}

Aunque lo antedicho ya explicita bastante la cuestión, debo plasmar las explicaciones que indican claramente las posturas. Esto es relevante si tenemos en cuenta que las decantaciones en pro de la gnoseología idealista y positivista en sus raíces más simples están prácticamente periclitadas, sobre todo la primera. Por otra parte, tenemos convergencias. En este sentido, Carr (1990) está mencionando y, como pendiendo parcialmente, de Peters; éste se asemeja a Woods y Moore en la yuxtaposición disciplinar, sin pedagogía, y Bokelmann (1981) posibilita una vía de integración. Después de la corrección popperiana respecto del positivismo y la práctica desaparición del idealismo, nos cuestionamos sobre la ubicación en alguna de las corrientes, ya que parece que están situadas en un abanico realista. Veamos de modo sucinto lo que nos expresan cada una de las tres perspectivas.

5.1. La corriente analítica presenta una aversión a reconocer la naturaleza política de la investigación educativa; aseguran que no hay por qué plantear influencia interactiva entre ambas esferas. Los únicos criterios para validar los hallazgos pedagógicos - educacionales - son la adecuación o no a las reglas del método elaborado para este fin.

Por consiguiente, habrá (Phillips, 1971) que separar el descubrimiento educacional del contexto de validación, en favor de una estrategia lógica objetiva. 
También habrá que separar la teoría - que es aséptica, sin carga valoral— de la validación; ya que en ésta si que hay valores.

Corolariamente, ¿Qué papel juega nuestra asignatura? Woods ofrece el enfoque multidisciplinar: "la educación es objeto de cuatro materias: filosofía de la educación, historia de la educación, psicología de la educación y sociología de la educación. No hay una conexión interdisciplinar porque no observan la necesidad de una integración en la raíz de la educación. Así, ¿Por qué no estudiar simplemente una disciplina de la educación? Y contesta él (p. 7): La respuesta más concisa a esta pregunta es que la educación — ¿Pedagogía? - no es una ciencia". En este sentido, Derden (1970) no sabe qué es un Pedagogo, pero sí un filósofo educacional, un psicopedagogo o un sociopedagogo. Peters (1963) está en una posición intermedia: un pedagogo sería un integrador de filosofía, psicología, sociología e historia. ¿No será ésta la otra acepción de educator, entendido como diferente a maestro y si como pedagogo? Sea como fuere, esta postura no deja de ser desintegradora. Los valores serían intrapolados en la teoría del educador a través de la sociología, que los capta en la sociedad, y nuestra materia ofrecería una explicación causal de los mecanismos de comportamiento, por psicología.

Por tanto, entiendo que necesitamos un enfoque metodológico, así como la coopresencia de diversas ciencias que estudien temáticamente la educación, pero sin suprimir un fuerte bagaje curricular de tipo pedagógico, siendo relevante el peso a dar para la teoría substantiva de la educación en sus diversos niveles.

5.2. La filosofía crítica (Mardones, 1990) parte de la sociología, generando la llamada crítica social. Bebiendo de Habermas, el exponente actual es el reiterado Carr (1990: 125 ss). Este plantea la siguiente línea discursiva:

$1^{\underline{a}}$ premisa: Nadie estudia educación - ¿Pedagogía? - sin estar comprometido antes con ciertos fines, valores y objetivos. Luego, la investigación académica está vinculada con valores educativos; aunque sea intencionalmente.

$2^{\mathrm{a}}$ premisa: La investigación no se puede descontextualizar. Para esto se fundan en Marx a través de Habermas (1972) y la Filosofía de la Ciencia (Brown, 1977) ha de arbitrar mecanismos para ello.

$3^{\text {a }}$ premisa: No hay por qué seguir los paradigmas dominantes, puesto que esto conlleva adherirse a ciertos valores de época.

4 premisa: Las ciencias sociales se fundamentan en la ciencia política y en la sociología.

$5^{\underline{a}}$ tesis: Integrar las metodologías de investigación. Cada una nos ofrece una orientación política.

Corolariamente, la investigación educativa sin valores y las teorías educativas cargadas de valor no son independientes, sino interdependientes; cualquier separación entre ellas es por razón de división de trabajo, pues los esquemas interpretativos (p. 129) contienen presupuestos metafísicos sobre la naturaleza humana.

Estas conclusiones pueden ser parecidas a nuestro enfoque, en tanto que asumimos una raíz antropológica para efectuar la integración y crítica teorética. No obstante, no tiene por que relacionarse la conclusión con cada una de las premisas. Entiendo que se da un salto epistemológico. La explicación se halla en la fun- 
damentación que menciona Carr (1990: 104) al identificar el contenido de la teoría con el de la educación: "una ciencia que es educativa -ipedagógica?-, porque no busca producir un saber 'objetivo' acerca de la educación, sino la especie de autoconocimiento crítico y reflexivo que la educación misma trata de fomentar y promover", esto es: los valores intelectuales y los principios democráticos.

La cuestión es si cabe este tipo de dialéctica. Esta es heredada de Hegel para subrayar el papel activo del sujeto, por tanto, de la importancia de las condiciones subjetivas y del voluntarismo en la praxis, para transformar el mundo, conforme el dictado de la II Internacional (Marsilla, 1970), pero que paulatinamente decae en una racionalidad utópica que rechaza la totalidad del mundo para refugiarse en sí misma. Surge así la crítica cultural, ideológica e institucional, atribuyendo a la educación la mera reproducción que combina marxismo con psicoanálisis. No observamos proposiciones operativas, sino pronósticos de un orden social racionalizado, en donde lo espiritual es supérfluo.

Por consiguiente, estamos lejos de perder la fundamentación antropológica previa, así como también rechazamos que la pedagogía penda de la sociología y la política. Esto es incompatible con la concepción autónoma de la ciencia de la educación, que pasamos a resumir.

5.3. La concepción autónoma parte de la acción educativa como centro de reflexión, en tanto que se efectúa una intervención de un educador sobre un educando, al menos, para producir cambios en su estado de personalidad. Se observa una referencia a un modelo deseado de persona, respecto al cual se elaboran tareas de orientación, modificación de actitudes y valores morales. Los valores son susceptibles de tratamiento sistemático, sirviendo de nexo para que el educador relacione medios con fines.

Esto no es ni la neutralidad de la analítica, ya que no es un juego impersonal, sino se produciría un desencarnar al educando, promoviendo en éste un esqueleto. Tampoco se efectúa la crítica, ya que ni uno ni otro asumen los valores alternativos, aunque el educador es consciente de su proyección vía el ejemplo. No cabe, pues el adoctrinamiento ni el uniformismo.

Se trata de que el educando reflexione sobre sí mismo y a su nivel; esto presupone una fundamentación de este mecanismo antropológico. Por consiguiente, los valores están en el fundamento de la teoría. Por tanto, la reflexión ha de ser tomada, no sólo con el fin de "entrenar" para el discurso racional, sino también para pensar el contenido teórico. Es lo que Jordán (8-9) señala como realizar juicios de valor que no pueden emerger de la mera combinación de ciencias de la educación.

En este contexto, es preciso (Escámez, 1989) conseguir cierto nivel de colaboración, que no es un conjunto de afirmaciones gratuitas, formuladas en proposiciones carentes de sentido, teniendo que buscar una validación indirecta en las acciones educativas y en conexión con las otras ciencias de la educación. Con esto se observa la conjugación interdisciplinar cuyo contenido consiste concretamente en despejar los juicios de valor interesados y particulares de las proposiciones generales teoréticas. 
Así, la investigación pedagógica no está supeditada a ciertos valores, sino de los enfoques teoréticos. Se efectuará crítica de investigación: si se observan intrapolaciones de efectos incontrolados en forma de teorías temáticas; no distinguir contextos específicos al enjuiciar las formulaciones de teorías generales; revisar la idea de ciencia pedagógica y enjuiciar constructos sobre el problema pedagógico. En suma, con Bokelmann (1981), relacionar la teoría de la ciencia con la teoría pedagógica para verificar la aplicabilidad de las teorías pedagógicas, ver si son admisibles los diversos enfoques y si es posible una metateoría común.

Así pues no se han de marginar los valores, al efectuar una objetivación, según las operaciones que propone Escámez (1989): a) analizar el lenguaje de las teorías pedagógicas; luego, b) revisar los conceptos fundamentales de éstas, y finalmente, c) reconstruir presupuestos antropológicos y axiológicos que operan en aquellas teorías.

Por tanto, epistemológicamente observamos la necesidad de efectuar un antirreduccionismo, no pasivo sino activo, congruente con el enfoque popperiano por vía ontológica (Mosterín, 1973). Por tanto, no es deseable aceptar proposiciones pedagógicas con carencias de significado en sus enunciados metafísicos. Por ejemplo: proponer discursos sobre áreas valorales sin concretar referencias a valores específicos. Así, ¿Qué significan valores intelectuales o estéticos como propuestas normativas? Una vía puede ser la crítica científica (Esteve y col., 1994: 131 ss) a las proposiciones normativas reduccionista del rol docente a la teoría apriorística de rasgos, en vez de plantearla en línea de las actitudes radicales en pro de la mejora.

Por consiguiente, aquí trato de concretar una reflexión conceptual con método que, sin concretar escalas de valores, esté abierta a la personalización. Esto despierta una racionalidad impregnada de interés crítico que replantea la descripción tradicional meramente analítica. O sea, hay que devolver al lenguaje su uso circunspecto para efectuar la crítica mediante clarificación. Verbi gratia: ¿Tal institución es congruente en su sistematización pedagógica? Por consiguiente, no estamos en contra de las otras ciencias no pedagógicas, pero consideramos cada realidad autónoma, y por tanto, conexionando teoría en la práctica sin yuxtaposiciones.

La justificación de esta proposición se funda en que la derivación de las ciencias positivistas de leyes y su inclusión en la fundamentación de la acción educativa, sólo por huir de "dar" valores es ya cierta ideología concreta. Lo plantea muy claro Artigas (1992: 169): "Debemos admitir que ha producido un terrorífico deterioro del respeto por la vida humana en algunos estratos de nuestra sociedad. Todo ello hace que sea especialmente urgente reafirmar en lo que sigue un punto de vista del que, según creo, no tenemos razón alguna para desviarnos: la opinión según la cual los hombres son fines en sí mismos y no meramente máquinas. Considero que la doctrina según la cual los hombres son máquinas no sólo está equivocada, sino que además es proclive a socavar la ética humanística.

Respecto a la cuestión, nos surgen interrogantes del siguiente orden: ¿Cómo falsearlas?, ¿No puede la teoría pedagógica pedir a tales proposiciones que extraigan las consecuencias prácticas de sus afirmaciones?, ¿Pueden expresarse tales formulaciones con claridad y honradez? Es a partir de aquí cuando podemos enjui- 
ciarlas y ubicarlas en la sistematización educativa, pero críticamente. No se trata de concebir como Moore una Teoría de la educación reducida a examinar las diversas teorías para ver su conformidad con lo que es conocido acerca de la naturaleza del hombre y su adecuación con las convicciones morales aceptadas (Ibáñez-Martín, 1990: 418). Como indica el Catedrático de la Complutense, hay que traspasar este discurso, preguntándose críticamente las razones sociales y a profundizar en el verdadero sentido de la naturaleza humana.

Por esto, el mero análisis del lenguaje lógico-abstracto, por anodino, no puede llegar a este nivel de reflexión. De aquí que efectuar la combinación de análisis lingüístico, con fenomenología, en un esquema racional-crítico sea conveniente para el desarrollo curricular, no sólo en la elaboración de la teoría pedagógica. Estamos, por tanto convergiendo con Hirts y Peters (1970). Así que, cuando propugnan educación, no como crecimiento, sino como iniciación axiológico-cultural, de modo racional-moral, pero esto ha de continuarse más allá de la sola explicación y proposiciones relativas a la comprensión. Pero, hay que añadirle convergentemente el sentido de formación.

La concreción de nuestra doctrina está pues alejada de una mera moral elaborada exclusivamente a partir de sólo encuestas. Esto no sólo no es Teoría de la educación, tampoco es Ética educativa; es Sociología. Es decir, uno de los enfoques que Woods efectúa de la Teoría de la Educación. Es la defensa del Crepúsculo del deber (Lipovetsky, 1994), que sustituye el deber por el individualismo, siguiendo la moda postmoderna. Su fundamento reside en la equiparación de ética con sociología, expresando lo que es sin discutir lo que debe-ser. Todo lo que sea obligación moral es tachado de intransigente y religioso. Así, toda la moral cae en un mismo montón: dogmatista y absolutista. Este es un recaer en el individualismo que confunde moral con sentimientos. Pero estos, aunque no son ajenos a la vida moral, ya que ésta no subsiste sin autoestima ni amor; también requiere capacidades de autocontrol, empatía, uso de la inteligencia.

Para efectuar este planteamiento, es necesario recuperar lo enunciado en el apartado sobre el modo de confeccionar la teoría científica: la referida noción de modelo. Desde este constructo el científico acomete la peculiar interpretación de la realidad. Desde una filosofía de la vida, hace su concepción del objeto de estudio. Lo que de manera más explícita se puede escribir con palabras de profesor Colom $(1983,148)$ : la teoría de la educación está impregnada de valores. Pero hay que concretar más esta afirmación, o al menos interpretarla. ¿Es que se trataría de trasladar los valores del profesor "A", "B" O "X"? No. Escámez (1988) plantea efectuar la crítica de los diseños desde los límites dados por la dignidad del sujeto; J. Ortega $(1978,145)$ considera que la acción educativa debe ser crítica frente a todo tipo de ideologías y estructuras que, analizadas dialécticamente, resulten injustas o limitantes de la libertad humana.

Por esto, la teoría científica es insuficiente para justificar racionalmente ciertos presupuestos (Escámez, 1989), por lo que ha de echar mano del recurso filosófico. Mas, por otra parte, la Ciencia de la educación genera, a través de los modelos, temática para que se elabore la teoría racional de la educación. Por ejemplo, ¿Hasta qué punto la tesis de Kohlberg puede mantenerse aisladamente 
de la enseñanza de actitudes? ¿Qué dice sobre esto la psicosociología respecto a las normas de los grupos en relación a la teoría del ajuste de la personalidad? ¿Y si la comunidad escolar plantea la asimilación de unos valores claramente jerarquizados y congruentes con la dignidad del hombre?

Puede que, al revés de algún que otro partidario de cierta concepción crítica, la solución no la puede ofrecer una sola persona, por muy carismática que fuere. ¿Con qué criterios se acuerda diseñar cierto modelo? Yager $(1985,144)$ ya recopila el modus faciendi, las academias científicas, expresándolo del siguiente modo: así es como también hacen los biólogos, fisiólogos, etc. Incluso hasta proponerse "an International Community in Science Education" (Symington, 1985, 145-146). Todo esto porque, como indica Popper (1977, 101), "los enunciados básicos se aceptan como resultado de una decisión o acuerdo, y desde este punto de vista son convenciones" que, siguiendo un proceder reglado, nos predisponen a "no deber aceptar enunciados básicos esporádicos, es decir, que no estén en conexión lógica con otros enunciados". Es lo que nos propone Tomas S. Kuhn, quien entiende que el concepto de ciencia normal es resultado de un consenso entre los miembros de la comunidad científica, apoyados en un paradigma construido como conjunto de presupuestos teóricos y principios que son aceptados como operativos para explicar la realidad en un determinado contexto histórico y cultural.

De aquí la relevancia de las academias científicas. Estas, concretando lo antedicho mediante las colaciones de grados universitarios, aportaciones científicas en los congresos y seminarios interuniversitarios o transnacionales, etc., en donde hay claras distinciones entre sistematización pedagógica y postura ideológica personal. Y, por supuesto, juzgando a los candidatos en las pruebas diversas para el acceso a las funciones docentes e investigadoras de las instituciones.

\section{Prescripciones para la práctica: La elaboración del CURRículum. Plan de Centro Y VALORES}

En suma: la ideología no tiene finalidad en sí misma, se trata de ofrecer un ambiente rico en valores, para que el sujeto integre los pertinentes con el fin de que estructure su yo de modo ajustado. Esto trae la necesidad de plantear los idearios de los centros como conjunto coherente de normas y valores. Consiguientemente, esto nos plantea relacionar las proposiciones con los interrogantes siguientes: ¿Cómo elaborar el proyecto educativo de los centros?; ¿Han de beber todos de idéntico ideario?; ¿Se ha de uniformizar el proyecto, por deductivismo como procedía el idealismo?, ¿Ha de procurarse una jerarquía de valores?; ¿El proyecto pedagógico se desprende de las directrices de los ministerios?; ¿Cómo han de intervenir los diversos estamentos de los colegios?, etc.

Este planteamiento tiene fundamental relevancia para la vida académica, centros de educación especializada, comarcas de desarrollo, etc. Toda institución se estructura en tres dimensiones culturales (Shipman): instructiva, formativa y expresiva. Tanto el ideario como el proyecto educativo es lo que da sentido a las partes. Por ver la relación de la doctrina gubernativa española con estos planteamientos, veamos el sentido que le dan. No se trata de una uniformización, Lucini 
(1990: 21) ve el ideario como presentación de alternativas de valor, comprometerse, aportar a alguna de las áreas axiológicas, sometiendo a las demás a un proceso de crítica razonada y objetiva.

Castillejo (1992, 25ss) distingue tres niveles en la estructuración curricular: a) el sujeto y el contexto (familia, centro, comunidad y ecológico); estos ocasionan unos b) diversos modos de adaptación curricular (individual, grupos específicos, niveles, centro y comunidad), y, para cada modalidad, tenemos c) las puestas en acción, como unidad de integración y desarrollo de experiencias, como ya decíamos en 1988. Marín Ibáñez (1993, 197) observa cuatro modos de posibilitar la fundamentación axiológica de los currícula: estatal, autonómico, de centro y en el aula, pero de modo complementario. Pero, ¿Es eso suficiente?, ¿Qué sentido presenta?

En el plano contextual, la Ley, concretada por los Diseños Curriculares Básicos atiende a la fuente sociológica, ceñida a las: a) demandas sociales y culturales del sistema educativo; b) conocimientos, procedimientos, actitudes y valores, como proceso de socialización, y c) asimilar saberes sociales y el patrimonio cultural. Por lo que la "escuela" es un subsistema de la sociedad (pp. 23 y 24). Otro enfoque es el dado por D'Hainaut $(1977,63)$ : “las fuentes primeras de los objetivos de la educación no son la sociedad, el estudiante ni el contenido de la enseñanza, sino más bien los valores, que determinan desde el comienzo las finalidades relativas a la sociedad, al estudiante o a la cultura y que intervienen en todas las etapas de una acción educativa". Es lo que dice Fermoso (1976, I-44): "los valores educativos están condicionados por los valores culturales y por la axiología general". Corolariamente, el modo de realizar valores por los sujetos es el operador para concretar el proyecto curricular de etapa y de aula, ya que la relación educando-asignatura se tiene como organizador de cada sesión de aprendizaje.

En este sentido, de cara a la elaboración de la teoría pedagógica, Peters (1969: 17 ss) indica que la sistematización de la educación con los juicios de valor genera una racionalidad pedagógica caracterizada por:

a) Explicar cómo condicionar a los niños a que capten ciertos asuntos sin tener conciencia de ello. Esto conduce a rebatir enfoques que estén vacíos de intencionalidad.

b) Lo que se aprende ha de considerarse valioso.

c) La forma de aprender se juzgará moralmente inobjetable, ya que no todo aprendizaje es educativo.

d) Señalar otra racionalidad, que no cabe en el discurso teorético, consistente en determinar: 1) estándares particulares de la virtud, y 2) qué rendimientos considerar valiosos y sus razones.

Estos últimos extremos nos llevan a pasar del discurso general sobre finalidades de la educación a otras más particulares que exigen la inclusión de la noción de aula, colegio, u otra unidad de educación. La cuestión estriba en plantear la problemática de la ideología en la sistematización pedagógica de los procesos de los centros escolares.

Al comienzo de este apartado observábamos con las aportaciones de la doctrina analítica que la racionalidad fáctica de educación está preñada de valores. Pero, 
desde este mismo enfoque observamos otra racionalidad. Es concretar los estándares particulares de virtud, los rendimientos que se consideran valiosos y las razones para ello. Pues bien, la hacedora de este otro procedimiento es la comunidad: "como los antropólogos, así también nosotros podemos referirnos al sistema educacional de una comunidad. Al emplear el concepto en este sentido derivativo, no necesitamos creer que lo que allí sucedía valía la pena: sólo sabemos que los miembros de esa sociedad así lo consideraban" (Peters, 1969: 19). Pero no nos engañemos, la apelación antropológica es por analogía y sin seguir la subalternancia. De esto nos avisa un antropólogo. Julio Caro Baroja (1995): ¿Se imagina uno a un flamante antropólogo de tierras nórdicas escribiendo sobre la burguesía de Madrid, lo que escribió Galdós en 'Fortunata y Jacinta'? No. Pero aún bay más. ¿Hasta qué punto el no participar en las inquietudes de una sociedad da autoridad para discutir acerca de la misma con exactitud? (...) ¡Cómo van a hablar de economia andaluza, por ejemplo, los que no hayan tenido ningún interés en ella! (...) Todos hablan 'desde fuera', 'aux pages', o dominados por ideologias rotundas. Pero poco oimos, para empezar, para seguir principios de objetividad, las voces de los que están o pueden estar metidos en el pleito y no se dejan llevar por las pasiones personales....

En suma. Las necesidades y aspiraciones humanas exigen la conquista del deber-ser, pero se da en un medio en donde se efectúa su "ethos". En esta yuxtaposición es en donde la acción del sujeto deviene en responsable, ya que exige la plasmación de su conciencia y su libertad. Al exigir responsabilidades en las acciones educativas, el hombre - varón y mujer - conquista su ser, su entidad ética. Esto significa que la estructuración del yo se lleva a cabo mediante el ajuste personal de valores, concretados en actitudes radicales, no a base de miedos.

Corolariamente, la situación del sistema escolar dentro de la Constitución de 1978, por el artículo 10, la persona es el eje respecto al cual estructurar los valores. De este modo sus principios de actuación: personalización, participación, igualdad, creatividad, democratización, autonomía de centros, orientación y actividad (Ley 1/1990; art. 2), han de tenerse en cuenta en los procesos de concreción de los que vamos a hablar.

Esto nos sobreavisa sobre los procesos de enseñanza-aprendizaje carentes de un corolario tendente a la toma de postura del educando. La mera transmisión de "patrones" culturales, o la sola gimnasia mental, o la "moral sin virtud" son insuficientes al plantear el diseño educativo. Siempre hay que dar cabida al "ethos", mantener en el espíritu educando la relación entre los hechos y el "deber ser". Es la necesidad consciente del hombre de la adquisición de un fin comprendido de antemano. Aunque este ámbito teleológico no esté realizado, no deja de ser una realidad de aspiración, de ser fundamentada.

Por estos fundamentos, efectuar la integración de los padres en los centros nos lleva a preguntarnos sobre los límites del deductivismo y del empirismo, ¿Cómo implicar procedimientos de uno y otro sin obviar la realidad?, ¿Seguir las directrices ministeriales sin más?, ¿Qué los padres se reeduquen mediante escuelas específicas?, ¿Contar con ellos sólo en cuestiones reglamentarias?, etc. ¿Cómo conciliar reduccionismos a través de la función pedagógica generada por la Teoría de la Educación elaborada no cientificistamente — no digo anticientificista—? 


\section{BiBLIOGRAFía}

ANDREws, S. W. (1995): Who Should be Teaching Values to Children?: Stakeholders in Moral Education. Contemporary Education, v. 66, n. 2, pp. 106-11, Win 1995.

BANKs, ElLen C. (1993): Moral Education in a Multicultural Context: The Malaysian Primary Curriculum. Paper presented at the Biennial Meeting of the Society for Research in Child Development (60th, New Orleans, LA, March 25-28, 1993).

BRown, Alan (1993): Spiritual and Moral Education: Where Does Responsibility Lie? Westminster Studies in Education, v. 16.

CARR, W. (1990): Hacia una ciencia crítica de la educación, Barcelona, Laertes.

Lenzen, D. (1988): “Mito, metáfora y simulación -Perspectivas de Pedagogía sistemática en la postmodernidad", en Educación, vol. 38. Tübingen, Instituto de Colaboración Científica.

BoKelmann (1981): Pedagogia, en Speck y Wehler.

BREZINKA, W. (1990): Conceptos básicos de la ciencia de la educación. Barcelona, Herder.

BREZINKA, W. y otros (1989): Hombre y educación. Barcelona, PPU.

BRUNER, J. (1987): La importancia de la educación. Buenos Aires, Paidós.

Bunge, M. (1972): La investigación científica. Barcelona, Ariel.

Bunge, M. (1981): La ciencia, su método y su filosofía. Buenos Aires, Siglo XX.

Bunge, M. (1985): Seudociencia e ideología. Madrid, Alianza.

CARR, W. (1990): Hacia una ciencia crítica de la educación. Barcelona, Laertes.

CASTILLA, B. (1994): Las coordenadas de la estructuración del yo. Pamplona, Eunsa.

Castillejo, J. L. (1987): Pedagogía tecnológica. Barcelona, CEAC.

CAstillejo, J. L.; Escamez, J. y MARín, R. (1981): Teoría de la educación. Madrid, Anaya.

CASTILlejo, J. L. y otros (1987): Investigación educativa y práctica escolar. Programas de acción en el aula. Madrid, Santillana.

CHOZA, J. (1988): Introducción a la antropología filosófica. Madrid, Rialp.

CHOZA, J. (1990): La realización del bombre en la cultura. Madrid, Rialp.

Cirigliano, G. F. J. (1973): Filosofía de la educación. Buenos Aires, Humanitas.

Colom, A. J. (1983): "Pedagogía social como modelo de intervención socioeducativa", Bordón, 247.

CORTiNa, A. (1985): Crítica y utopia: la escuela de Francfort. Madrid, Cincel.

DEARDEN, R. F. (1982): Educación y desarrollo de la razón. Madrid, Narcea.

DEARDEN, R. F. (1992): Teoría y práctica de la educación, en: La filosofía de la educación en Europa, ob. cit.

D'Hainaut, L. (1977): Des fins aux objectifs de l'éducation. París, Fernand Nathan.

Dewey, J. (1957): Democracia y educación. Buenos Aires, Losada.

DiESSNER, Rhett (1991): Teacher Education for Democratic Classrooms: Moral Reasoning and Ideology Critique. Draft. Seminar paper presented at the Annual Meeting of the Association for Moral Education (16th, Athens, GA, November 1991).

EsCÁmEZ, J. (1981): La formación de bábitos como objetivos educativos. Universidad de Murcia.

Escámez, J. (1986): Los valores en la pedagogía de la intervención, en Castillejo, J. L.: Tecnología y educación. Barcelona, CEAC.

ESCÁMEZ, J. (1981): "Fundamentación antropológica de la educación", en Teoría de la educación. Madrid, Anaya.

EsCÁmeZ, J. (1983): “Educación y normatividad”, en Teoría de la educación I. Murcia, Límites (hoy en CEAC). 
Escámez, J. (1986): “Los valores en la pedagogía de la intervención", en Papers d'educació. Conceptos y propuestas III. Valencia, Nau-llibres.

Escámez, J. (1988): La teoría pedagógica y el progreso educativo, Actas del IX Congreso Nacional de Pedagogía. Alicante, SEP.

EsCÁMEZ, J. (1992): La filosofía de la educación como praxis educativa, en: La filosofía de la educación en Europa. Madrid, Dykinson.

EscÁmez, J. y Ortega, P. (1986): La enseñanza de actitudes y de valores. Valencia, Nau-llibres. ESTEVE, J. M. (1979): Lenguaje educativo y teorías pedagógicas. Madrid, Anaya.

EsteVE, J. M. (1981): "El concepto de educación y su red nomológica". Teoría de la educación-I. Murcia, Límites.

EsTEVE, J. M. y colaboradores (1994): Metodología didáctica en Teoría de la educación, Revista de Ciencias de la Educación, 157.

Fermoso, P. (1976): Teoría de la educación. Madrid, Agulló.

Fermoso, P. (1976): Crisis de valores y crisis educativas, en: Actas del VI Congreso Nacional de Pedagogia. Madird, CSIC.

Fermoso, P. (1988/89): El modelo fenomenológico de investigación en Pedagogía Social, Educar, núms. 14-15. Bellaterra. Universidad Autónoma de Barcelona.

García-Carrasco, J. y García del Dujo, A. (1996): Teoria de la Educación I. Ediciones Universidad de Salamanca.

García Hoz, V. (1981): Principios de pedagogía sistemática. Madrid, Rialp.

IBÁÑEZ-LANGLOIS, J. M. (1978): Introducción a la antropología filosófica. Pamplona, Nuestro Tiempo.

IBÁÑEZ-MARTín, J. A. (1975): Hacia una formación bumanística. Barcelona, Herder.

IBÁÑ̃Z-MARTín, J. A. (1982): “La formación pedagógica del profesorado y el plural concepto de filosofía de la educación", en Revista Española de Pedagogía, núm. 158.

IBÁÑez-Martín, J. A. (1989): “El papel de la teoría de la educación en la formación del profesorado", cfr. Esteve, 1989-Ed.

Keat, Marilyn-S. (1992): Beyond the Virtues-Principles Debate. Educational-Theory, v. 42, n. 4, pp. 443-69, Fall 1992.

Lipovetsky, G. (1994): El crepúsculo del deber. Barcelona, Anagrama.

MARÍN, R. (1993): Los valores. Madrid, S.M.

MaRín, R. (1976): Valores, objetivos y actitudes en educación. Valladolid, Miñón.

Marín, R. (1983): "La educación como optimización del hombre", en: Teoría de la educación I. Murcia, Límites (actualmente, CEAC).

McEwan, Bárbara (1990): Judicious Discipline: Citizenship Values as a Framework for Moral Education. Sin referencia en Eric, núm. ED338524.

MOORE, T. W. (1980): Introducción a la teoria de la educación. Madrid, Alianza.

MurguenZA, J. (1971): Nuevas perspectivas en la filosofía contemporánea de la ciencia, Theorema, $\mathrm{I} / 3$.

NAssif, R. (1965): Pedagogía de nuestro tiempo. Buenos Aires. Kapelusz.

NASSIF, R. (1980): Pedagogía General. Madrid, Kapelusz.

NAssif, R. (1983): Teoría de la educación. Madrid, Cincel.

Naval, C. (1995): Educar ciudadanos. Pamplona, Eunsa.

NAVAL, C. (1996): Las demandas educativas de la diversidad: entre la neutralidad y el multiculturalismo. Antropología y educación. III Congreso Internacional de Filosofía de la Educación. UNED, Madrid.

Ortega, J. (1978): Hacia una ciencia de la educación, en AA.VV.: Epistemología y educación. Salamanca, Sígueme.

ORTEGA, J. (1978): Delincuencia, reformatorio y educación liberadora. Madrid. Zero-ZYX.

(C) Ediciones Universidad de Salamanca

Teor. educ. 9, 1997, pp. 93-113 
Paul, Richard-W.; Binker, A. J. A. (Ed. 1990): Critical Thinking: What Every Person Needs To Survive in a Rapidly Changing World. Sonoma State Univ, Rohnert Park, CA. Center for Critical Thinking and Moral Critique.

Peters, R. S. (1969): El concepto de educación. Buenos Aires, Paidós.

PHILLPS, H. E. (1991): Special problems in teaching of modern philosophy. Teaching Philosophy, vol. 13, núm. 3.

Piaget, J. (1967): A dónde va la educación. Barcelona, Teide.

Popper, K. (1967): La sociedad abierta. Buenos Aires, Paidós.

Popper, K. (1992): "La sociedad abierta hoy", Blanco y negro, 3784, año C, 5 de enero.

POPPER, K. R. (1973): La lógica de la investigación científica. Madrid, Tecnos.

Popper, K. R. (1982): Conocimiento objetivo. Madrid, Tecnos.

POURTOIS, J. P. y DESMET, H. (1988): Epistemologie et instrumentation en sciences bumaines. Bruselas, Mardaga.

Quintana, J. M. (1988): Teoría de la educación. Madrid, Dykinson.

RACIONERO, L. (1996): El origen de los valores, $A B C$ (5-VII).

SANDín, Robert-T. (1992): The Rehabilitation of Virtue: Foundations of Moral Education. Praeger Publishers, One Madison Avenue, New York.

SARRAMONA, J. (1986): "La pedagogía como ciencia tecnológica", Revista de educación, núm. 280, Madrid.

Sarramona, J. (1986): "Ciencia y tecnología en educación”, Bordón, núm. 263.

SARRAMONA, J. (1989): "Los contenidos del currículum", cfr. Esteve, 1989-ed.

SARRAMONA, J. (1988/89): "El concepte de racionalitàt en tecnología educativa”, Educar, 1415. UAB, Bellaterra.

SCHEFFLER, I. (1969): Confr. Peters.

Shipmann, M. D. (1973): Sociologia escolar. Madrid, Morata.

SPECK, J. y WeHLE, G. (1981): Conceptos fundamentales de pedagogia. Barcelona, Herder.

STURN, Johan-C. (1993): Education between Indoctrination and Emancipation. Religious education; v. 88, n. 1, pp. 40-51, Win 1993.

Touriñán, J. M. (1987): Teoría de la educación. Madrid, Anaya.

TOURIÑÁn, J. M. (1987): Estatuto del profesorado. Madrid, Magisterio Español

Touriñán, J. M. (1989): "Las finalidades de la educación: análisis teórico”, en Esteve, 1989ed.

VolPI, C. (1986): "Tareas y funciones de la pedagogía social", Revista de pedagogía social, núm. 1.

Woods, R. G. (1976): Filosofía de la educación, en Woods, R. G. Edit.: Introducción a las ciencias de la educación. Madird, Anaya.

WRIGHT, G. H. (1975): Norma y acción. Una investigación lógica. Madrid. Tecnos.

YAGER, R. E. (1985): "In defense of defining science education as the science/society interface", Science Education, 69 (2).

Yuren, María T. (1980): Leyes, teorias y modelos. México, Trillas. 